\title{
Dominant effect of relative tropical Atlantic warming on major hurricane occurrence
}

\author{
H. Murakami1',2*+, E. Levin ${ }^{3}$, T. L. Delworth ${ }^{1,2}$, R. Gudgel', P.-C. Hsu ${ }^{4}$ \\ ${ }^{1}$ National Oceanic and Atmospheric Administration/Geophysical Fluid Dynamics Laboratory, Princeton, NJ, USA. ${ }^{2}$ Atmospheric and Oceanic Sciences Program, Princeton \\ University, Princeton, NJ, USA. ${ }^{3}$ Paul D. Schreiber High School, Port Washington, NY, USA. "Key Laboratory of Meteorological Disaster of Ministry of Education, Nanjing \\ University of Information Science and Technology, China. \\ *Corresponding author. Email: hir.murakami@gmail.com \\ †Present address: University Corporation for Atmospheric Research, Princeton, NJ, USA. \\ We explore factors potentially linked to the enhanced major hurricane activity in the Atlantic during 2017. \\ Using a suite of high-resolution model experiments, we show that the increase in 2017 major hurricanes \\ was not primarily caused by La Niña conditions in the Pacific Ocean, but mainly by pronounced warm sea \\ surface conditions in the tropical North Atlantic. It is further shown that, in the future, a similar pattern of \\ North Atlantic surface warming, superimposed upon long-term increasing sea surface temperature from \\ increases in greenhouse gas concentrations and decreases in aerosols, will likely lead to even higher \\ numbers of major hurricanes. The key factor controlling Atlantic major hurricane activity appears to be \\ how much the tropical Atlantic warms relative to the rest of the global ocean.
}

The 2017 hurricane season in the North Atlantic Ocean was highly active, with six major hurricanes (MHs) - including three that made landfall (Hurricanes Harvey, Irma, and Maria) - causing widespread socio-economic damage over the Gulf Coast and the Caribbean (1,2) (Fig. 1, A and C). Considering the mean seasonal $\mathrm{MH}$ number (2.7) and its standard deviation (1.9) during the period 1979-2017 (Fig. 1B), the positive anomaly of $\mathrm{MH}$ was almost two standard deviations above normal. Specifically, and importantly, among these six MHs in 2017, Hurricanes Harvey, Irma, and Maria made landfall over the Gulf coast and the Caribbean (Fig. 1, A and C), causing substantial socio-economic damage in these coastal regions (2). Moreover, Hurricane Harvey ended a 12-year period of no landfalling MHs in the US [the so-called "MH landfall drought" $(3,4)]$, with the most recent landfalling MH (Hurricane Wilma) having occurred in 2005. The highly active MH season in 2017 has attracted considerable attention throughout the scientific community (5), as well as broader society (6), not only in terms of its causes, but also whether anthropogenic forcing played a role (2).

A number of factors might have caused the active $\mathrm{MH}$ season. The boreal summer season in 2017 was characterized by a developing moderate La Niña and associated conditions [see region A in Fig. 1D; the Niño3.4 index was 0.4 standard deviations below normal (Fig. 1B)]. It is known that, during summers with a developing La Niña, hurricanes are more active over the North Atlantic due to a weakening of the vertical shear of the zonal winds over the tropical Atlantic relative to climatology $(7,8)$. The correlation coefficient (hereafter, $r$ ) between the Niño3.4 index and the observed MH frequency for the period 1979-2017 is -0.45 , which is statistically significant ( $p$-value $<0.01$; Fig. 1B). It is also apparent that the surface ocean in boreal summer 2017 was substantially warmer than the climatological mean in the tropical North Atlantic, where most tropical cyclones are generated [the SST anomaly (SSTA) was 1.5 standard deviations above normal in region B in Fig. 1D, hereafter referred to as the main developing region (MDR); fig. S1]. Based on observations over the last 60 years, Kossin (9) reported that ambient environmental vertical wind shear (10-12), which is defined as wind speed difference between upper troposphere $(200 \mathrm{hPa})$ and lower troposphere $(850 \mathrm{hPa})$ and considered as a detrimental factor for tropical cyclone genesis and intensification, tends to be stronger off the east coast of the U.S. (region C in Fig. 1D) when SST is higher over region $\mathrm{B}$, leading to less major hurricanes over region C. However, this relationship is not clear for the 2017 summer. Observations for the 2017 summer within region $\mathrm{C}$ show a mixture of wind shear anomalies (fig. S2A): weaker in the Gulf of Mexico and stronger along the Canadian coast despite the positive SSTA over region B. Meanwhile, a substantial positive SSTA was also observed over region C. It is expected that tropical cyclones obtain more energy from warmer oceans, and then further develop into MHs during their westward propagation from the MDR.

Overall, the SSTA spatial pattern in 2017 over the North Atlantic resembles a positive phase of the Atlantic Multidecadal Oscillation (AMO) (13). The observed AMO index is 1.5 standard deviations above its long-term mean for the 2017 summer season (Fig. 1B). Indeed, the AMO index is 
moderately and positively correlated with the number of MHs for the period 1979-2017 ( $r=+0.50$; $p$-value < 0.01; Fig. 1B). There is, however, another mode of variability over the region: the Atlantic Meridional Mode (AMM) (14). The AMM has substantial variability at the interannual time scale in the North Atlantic, characterized by a meridional contrast in the SSTA across the Equator, as well as associated surface wind anomalies. The correlation coefficient between the observed $\mathrm{AMM}$ index and MH frequency is $+0.62(p$-value $<0.01$; Fig. $1 B$ ), and the observed AMM index for the 2017 summer season was 1.2 standard deviations above normal. These high positive indices imply a possible impact of internal natural variability on this active $\mathrm{MH}$ season in 2017 (15). However, it is also possible that greenhouse-induced global warming might have caused the emergence of the pronounced $\mathrm{MH}$ activity in the 2017 hurricane season. This is based on the findings of several previous modeling studies that commonly projected an increase in intense storms like MHs under conditions of increased anthropogenic forcing (16-18). In this study, using a suite of high-resolution model experiments (19, 20 ), we attempt to elucidate what the physical reasons are for the occurrence of the active $2017 \mathrm{MH}$ season as well as possible future changes in $\mathrm{MH}$ activity in the future given similar 2017 summer conditions in the future, but with increased anthropogenic forcing.

\section{Successful prediction of active $2017 \mathrm{MHs}$}

The particularly active MH season in 2017 was predicted well in real-time seasonal predictions starting from initial conditions on 1 July using a high-resolution global coupled model [HiFLOR $(19,20)]$ developed at the Geophysical Fluid Dynamics Laboratory. Previous studies have shown that HiFLOR can simulate the observed interannual variation of $\mathrm{MH}$ frequency in historical simulations (19), and offers skill in retrospective seasonal predictions (20) (the $r$ between the predicted and observed MH frequency is +0.74 for the period 1980-2017; see fig. S3). Figure 1E shows the predicted 2017 seasonal-mean $\mathrm{MH}$ density anomaly (July-November) from initial conditions on 1 July 2017 (i.e., lead month $=0-4$ ), which can be contrasted with the corresponding observations in Fig. 1C. HiFLOR successfully predicted the observed higher MH density along the eastern coast of the Caribbean and Florida, although the predicted density anomalies were underestimated. It is also notable that HiFLOR realistically predicted the spatial pattern of the MH density anomaly over the Pacific Ocean as well. Because in these real-time seasonal predictions the oceanic conditions were initialized but the atmospheric and land-surface were not, the successful prediction mainly derives from the oceanic state, along with the prescribed boundary conditions of anthropogenic forcing $(8,20)$. Indeed, HiFLOR predicted a higher SSTA over the Atlantic, especially over the MDR and off the east coast of the
U.S., in addition to the moderate La Niña conditions as observed (Fig. 1, D and F). However, the amplitude of the La Niña conditions was underestimated in the real-time predictions. HiFLOR also largely predicted the spatial pattern of vertical wind shear anomalies (fig. S2, B and C) compared to observations (fig. S2A); however, there are some differences between predictions and observations at small regional scales.

Observations show that the MHs in 2017 primarily occurred during a confined period in the late summer season (26th Aug - 14th Oct; black solid line in fig. S4) which is a subset of the climatological MH season (July - October; black dashed line in fig. S4). This clustering indicates an important role for subseasonal oscillations for the timing of $2017 \mathrm{MHs}$ $(21,22)$. HiFLOR failed to predict the timing of active MHs in 2017. Figure S4 shows that 2017 MHs (blue thick line) were predicted to occur earlier than the modeled climatological mean MH season (red thick line). However, we did not expect that the HiFLOR could predict the timing of the active MHs for 2017 because the atmosphere was not initialized in the predictions. Given the fact that a few ensemble members show active MHs during the late 2017 summer season (blue thin lines in fig. S4) it appears that HiFLOR is able to simulate subseasonal oscillations comparable to observed (19), and that inclusion of atmospheric initialization may potentially improve predictions of the timing of the MHs during 2017.

\section{Reasons for the active $2017 \mathrm{MH}$ season}

To elucidate the relative importance of SSTAs in various regions for the occurrence of this highly active $2017 \mathrm{MH}$ season, we used HiFLOR to conduct a series of idealized seasonal predictions for the period 1 July through 30 November. In these idealized predictions, SST in the model was restored to the SSTs from the original HiFLOR seasonal predictions initialized from 1 July 2017, but with some modifications [we refer to the SST-restoring experiments as "nudging experiments" (19) (see supplementary method c)]. In the first nudging experiment, we restored the SST to the predicted climatological mean SST computed over the period 1982-2012, which we call CLIM. In the second experiment, we restored the SST to the SST predicted for 2017, which we call CLIM+ (Fig. 2A). The CLIM and CLIM+ simulations yielded about three and six MHs, respectively (Fig. 3). These simulated values were close to the observed values for the climatology (2.7) and the 2017 season (6). Moreover, the pattern of the predicted MH density anomaly in CLIM+ (right-hand panel of Fig. 2A) reflected the observed $2017 \mathrm{MH}$ density anomaly in the North Atlantic (Fig. 1C). The fidelity of the MH prediction by HiFLOR gave us confidence in carrying out further sensitivity experiments with the model.

In the next sensitivity experiment, we used the SSTs from 
CLIM+, except the SSTs over the Pacific Ocean were replaced with those from CLIM. We refer to this experiment as PCLIM, and the results are shown in Fig. 2B. If the 2017 La Niña conditions indeed led to the particularly active $\mathrm{MH}$ season in 2017, the predicted MH frequency should have been reduced in the PCLIM experiment. However, the results (Figs. 2B and 3 ) show this was not the case. Therefore, the moderate 2017 La Niña conditions were not the key factor for the highly active $\mathrm{MH}$ season in 2017. Unlike the predictions started from initial conditions on 1 July 2017, the HiFLOR real-time seasonal predictions started from initial conditions on 1 April 2017 predicted a strong El Niño development for the 2017 summer season. This false alarm has also been predicted by other seasonal prediction models (23), possibly associated with the so-called "spring predictability barrier (24)." In our next sensitivity test, we replaced the CLIM+ SST over the Pacific Ocean with the predicted SST from the April forecasts to emulate a strong El Niño condition, which we refer to as experiment PEL. Although the MH frequency in PEL decreased slightly relative to CLIM+, the PEL prediction still showed active MHs over the North Atlantic (Fig. 2C and 3), indicating the possibility of high $\mathrm{MH}$ activity in the Atlantic even with El Niño conditions during summer 2017. These experiments support the assertion that the Pacific SSTA in 2017 was not a critical factor for the particularly active $\mathrm{MH}$ season in the North Atlantic that year.

Next, we conducted an experiment similar to CLIM+, but with the Atlantic SST replaced by the CLIM SST (ACLIM; Fig. 2D). The ACLIM prediction showed significant reductions in both $\mathrm{MH}$ number and density (Figs. 2D and 3), suggesting that the local Atlantic SSTA was critical for the high MH activity in 2017. Furthermore, we separately replaced the SST with the CLIM SST in the region off the east coast of the U.S. (GCLIM; Fig. 2E) and in the MDR (MCLIM; Fig. 2F), and found that replacing the MDR SSTA substantially reduced the $\mathrm{MH}$ frequency and $\mathrm{MH}$ density (Figs. $2 \mathrm{~F}$ and 3). In contrast, results from GCLIM led us to conclude that the SSTA off the east coast of the U.S. was not a major factor controlling the unusually high $\mathrm{MH}$ activity in the 2017 hurricane season in terms of the number of MHs.

Note that we utilized the predicted SSTs, rather than observed SSTs, for the lower boundary conditions throughout this study (supplementary method c). This is because we started this attribution study before the end of the 2017 hurricane season (i.e., real-time event attribution study) when observed SSTs are unavailable. Meanwhile, we confirmed that the same conclusions could be obtained even using observed SSTs (figs. S5 and S6).

\section{Effect of anthropogenic forcing on active MH season}

Another open question is to what extent the increase in anthropogenic forcing influenced the emergence of this particularly active MH season in 2017. To investigate this, we followed the idealized seasonal-prediction framework, but additionally considered potential future conditions (see supplementary method c). The RCP4.5 and RCP8.5 experiments, in which future changes in mean SSTs according to CMIP5 models (fig. S7) were superimposed onto the CLIM SST, respectively resulted in more frequent MHs relative to CLIM by about 1.5 and 2.0, with statistical significance ( $p$-values of $<$ 0.05 and < 0.01; Fig. 3), and a basin-wide increase in $\mathrm{MH}$ density (Fig. 4, A and B), albeit with both RCP4.5 and RCP8.5 also showing a marked increase in MH density in the Northern Atlantic and Gulf of Mexico. These results imply a general increase in $\mathrm{MH}$ occurrence induced by anthropogenic forcing. The RCP4.5 and RCP8.5 runs showed a slight reduction in $\mathrm{MH}$ density along the location of maximum $\mathrm{MH}$ density in CLIM (i.e., maximum contour in Fig. 4, A and B), but the reduction was not statistically significant. This noisy spatial pattern of changes may have been caused by the small sampling size in the predictions (i.e., 12 ensemble members). To increase the sample size, we conducted another set of longterm (200-yr) control simulations ${ }^{6}$ by fixing the level of anthropogenic forcing to that in 2015 (2015Cntl) and 1940 (1940Cntl) (see supplementary method b). These simulations showed a basin-wide increase in MH density in $2015 \mathrm{Cntl}$ relative to $1940 \mathrm{Cntl}$ (Fig. 4C).

In addition to the RCP4.5 and RCP8.5 experiments, we superimposed the 2017 SSTA (Fig. 2A) onto the SSTs from the RCP4.5 and RCP8.5 experiments to mimic the impact of the 2017 spatial distribution of SSTAs if that pattern were to occur in a future warmer climate. These experiments, which we refer to as RCP4.5+ and RCP8.5+, showed an increase in the number of MHs by about three relative to their future meanstate experiments (i.e., RCP4.5 and RCP8.5) (Fig. 3). The increase of three MHs was similar to that from the present-day experiments (i.e., CLIM+ minus CLIM in Fig. 3), suggesting that the increase in MH activity induced by the 2017 SSTA was not highly sensitive to the mean climate state. The increase in MHs induced by the 2017 SSTA (i.e., $+3 \mathrm{MHs}$ ) was larger than that by the mean-state changes (i.e., +1.5-2.0 MHs; Fig. 3), indicating a greater influence of the 2017 SSTA than the mean-state change on the unusually high $\mathrm{MH}$ activity that year. The MH density anomalies projected by $\mathrm{RCP} 4.5+$ and $\mathrm{RCP} 8.5+$ relative to their mean-state experiments (Fig. 4, D and E) show a similar spatial pattern to the 2017 MH anomaly (Fig. 4F), but with a higher MH density over the Caribbean and near the U.S. coast, amplifying the risk of MHs over these regions, as well as a higher MH density over the open ocean in the northern North Atlantic.

Another possible factor responsible for the unusually active $\mathrm{MH}$ season in 2017 was the external influence of anthropogenic aerosols. Dunstone et al. (25) reported that their dynamical model led to anthropogenic aerosols lowering the 
frequency of tropical storms over the 20th century, while sharp declines in anthropogenic aerosol levels over the North Atlantic at the end of the 20th century increased the number of tropical storms. Based on climate model simulations, recent studies $(26,27)$ also reported that the potential intensity, the theoretical upper limit of the storm intensity given the large-scale environment, recently started to increase due to reductions in anthropogenic aerosols over global domain (27) as well as in the North Atlantic (26), indicating potential increases in $\mathrm{MH}$ frequencies due to decreases in anthropogenic aerosol forcing. To investigate the influence of aerosols on the $\mathrm{MH}$ frequency, we conducted an additional idealized seasonal nudging prediction, with similar settings as CLIM+, except that the estimated SSTA due to a reduced concentration of anthropogenic aerosols (fig. S8) was superimposed onto the CLIM+ SST (hereafter, AERO+; see supplementary method c). It was confirmed that the AERO+ experiment did increase the MH frequency slightly (by +0.8 ) relative to the CLIM+ experiment (Fig. 3), qualitatively supporting the conclusion of previous studies (25-27), even for the $\mathrm{MH}$ frequency. However, the increase is not statistically significant ( $p$-value = 0.19). As discussed in Murakami et al. $(28)$, the projected impact of aerosols on $\mathrm{MH}$ frequency may be underestimated in HiFLOR because the model may underestimate the radiative forcing by aerosols due to a lack of representation of the indirect effects of aerosols. Further refinement of the model's physics is necessary to better estimate the impact of aerosols on $\mathrm{MH}$ frequency.

\section{Relative importance of relative SSTAs on active MH sea- son}

Previous studies $(29,30)$ have reported the frequency of hurricanes (i.e., weaker than MHs) to be positively correlated with the MDR SSTA (the SSTA in domain B in Fig. 1C; 10$25^{\circ} \mathrm{N}, 80-20^{\circ} \mathrm{W}$ ), as well as the relative SSTA (RSSTA), which is defined as the difference in SST between the mean SST over the MDR and the mean SST over the global tropics $\left(30^{\circ} \mathrm{S}-\right.$ $30^{\circ} \mathrm{N}$ ). This is also true for MHs. The correlation coefficient between observed MH frequency and MDR SSTA (RSSTA) was $+0.50(+0.61)$ for the period 1979-2017. The standardized value for $\mathrm{MH}$ frequency for the 2017 summer season was 1.1 (0.8) standard deviations above its long-term mean (fig. S1). A recent study (15) also reported there to be a positive correlation between the observed MH frequency and the RSSTA on the decadal time scale. However, it is uncertain if these positive correlations hold true for MHs in the future. The response of MHs to anthropogenic warming might be different to that of weaker storms because, as reported in several previous studies, the global number of weaker storms will likely decrease in a warmer environment in the future, whereas that of intense storms will increase (16-18). Figure 5, A and $\mathrm{B}$, shows a moderate and positive correlation of the predicted
MH frequency with both the MDR SSTA and RSST, based on a series of idealized nudging experiments in the present-day framework (i.e., the RCP experiments are not included in these figures). The correlation ( $r$ ) between the $\mathrm{MH}$ frequency and MDR SSTA was +0.56 and the slope of linear regression (hereafter, $a$ ) was $+5.06 \mathrm{~K}^{-1}-$ similar to the values for the RSSTA $\left(r=+0.56\right.$ and $\left.a=+5.80 \mathrm{~K}^{-1}\right)$. However, when we included the RCP experiments in this analysis, the values of $r$ and $a$ for the MDR SSTA dropped sharply from the original values (Fig. 5, A and C), whereas for RSSTA they remained almost the same as the original values (Fig. 5, B and D). To further clarify these relationships, we conducted an additional nudging experiment (P3K; see supplementary method c) with the CLIM SST plus a globally uniform $+3 \mathrm{~K}$ (i.e., zero RSSTA change) with other settings identical to the RCP8.5 experiment. P3K showed a slight increase in $\mathrm{MH}$ frequency relative to CLIM (Fig. 3), but not as large as RCP8.5+, resulting in a lowering of the positive correlation between the MDR SSTA and MH frequency. Overall, our results support the hypothesis that the $\mathrm{MH}$ frequency over the North Atlantic is highly correlated with the RSST - at least with this model.

\section{Discussions}

Overall, the results from our series of idealized experiments show that the enhanced MH activity in the Atlantic in 2017 was mainly caused by the larger SSTA over the MDR relative to the rest of the global ocean, rather than by the moderate La Niña conditions. However, this does not mean that the $\mathrm{MH}$ frequency and spatial distribution in the Atlantic are always insensitive to ENSO. As documented in previous studies $(19,31)$, HiFLOR can capture the observed contrast in $\mathrm{MH}$ activity in the North Atlantic in different ENSO phases. We speculate that in 2017 the effect of the MDR SSTA was large enough to increase the $\mathrm{MH}$ activity regardless of the remote effects of any phase of ENSO. The higher tropical North Atlantic SSTA was possibly associated with a specific phase of natural variability, like the positive phase of the AMO or AMM. However, it is also possible that to some degree the 2017 SSTA contained the effects of anthropogenic forcing too, although we cannot separate the two factors at this moment. It also remains uncertain as to whether we will see more of these active hurricane seasons, like that of 2017, in the ensuing decades, despite the arguably strong indicator of having experienced two successive active MH seasons since 2016 (Fig. 1B). This is because a recent study (15) suggested a significant reduction in MHs since 2005 on the decadal time scale in association with a weakening of the Atlantic meridional overturning circulation (AMOC). Monitoring AMOC and RSST anomalies are key to predicting the MH activity of the future; although, according to the moderate correlation in our study $(r=+0.61)$ between the RSST anomaly and MH frequency in observations (fig. S1), the RSST anomaly is not the 
only factor determining the $\mathrm{MH}$ frequency in the North Atlantic. Further research that addresses the physical mechanisms underpinning highly active $\mathrm{MH}$ seasons is necessary.

\section{REFERENCES AND NOTES}

1. CNN, A look at four storms from one brutal hurricane season; available online at www.cnn.com/2017/10/10/weather/hurricane-nate-maria-irma-harveyimpact-look-back-trnd/index.html.

2. K. Emanuel, Assessing the present and future probability of Hurricane Harvey's rainfall. Proc. Natl. Acad. Sci. U.S.A. 114, 12681-12684 (2017). doi:10.1073/pnas.1716222114 Medline

3. T. Hall, K. Hereid, The frequency and duration of U.S. hurricane droughts. Geophys. Res. Lett. 42, 3482-3485 (2015). doi:10.1002/2015GL 063652

4. B. E. Hart, D. R. Chavas, M. P. Guishard, The arbitrary definition of the current Atlantic major hurricane landfall drought. Bull. Am. Meteorol. Soc. 97, 713-722 (2016). doi:10.1175/BAMS-D-15-00185.1

5. E. Shuckburgh, D. Mitchell, P. Stott, Hurricanes Harvey, Irma and Maria: How natural were these 'natural disasters'? Weather 72, 353-354 (2017). doi:10.1002/wea. 3190

6. Vox, Hurricane season 2017: What the hell just happened?; available online at www.vox.com/energy-and-environment/2017/10/25/16504488/hurricaneseason-2017-what-the-hell.

7. S. B. Goldenberg, L. J. Shapiro, Physical mechanisms for the association of El Niño and west African rainfall with Atlantic major hurricane activity. J. Clim. 9, 11691187 (1996). doi:10.1175/1520-0442(1996)009<1169:PMFTAO>2.0.C0;2

8. D. M. Smith, R. Eade, N. J. Dunstone, D. Fereday, J. M. Murphy, H. Pohlmann, A. A. Scaife, Skilful multi-year predictions of Atlantic hurricane frequency. Nat. Geosci. 3, 846-849 (2010). doi:10.1038/ngeo1004

9. J. P. Kossin, Hurricane intensification along United States coast suppressed during active hurricane periods. Nature 541, 390-393 (2017). doi:10.1038/nature20783 Medline

10. M. DeMaria, The effect of vertical shear on tropical cyclone intensity change. J. Atmos. Sci. 53, 2076-2088 (1996). doi:10.1175/15200469(1996)053<2076:TEOVSO $>2.0 .00: 2$

11. R. L. Elsberry, R. A. Jeffries, Vertical wind shear influences on tropical cyclone formation and intensification during TCM-92 and TCM-93. Mon. Weather Rev. 124, 1374-1387 (1996). doi:10.1175/1520-0493(1996)124<1374:VWSIOT>2.0.C0;2

12. M. L. M. Wong, J. C. L. Chan, Tropical cyclone intensity in vertical wind shear. J. $\begin{array}{llll}\text { Atmos. Sci. 61, 1859-1876 (2004). doi:10.1175/1520- } & \end{array}$ 0469(2004)061<1859:TCIIVW>2.0.C0:2

13. T. L. Delworth, M. E. Mann, Observed and simulated multidecadal variability in the Northern Hemisphere. Clim. Dyn. 16, 661-676 (2000). doi: $10.1007 / \mathrm{s} 003820000075$

14. D. J. Vimont, J. P. Kossin, The Atlantic meridional mode and hurricane activity. Geophys. Res. Lett. 34, L07709 (2007). doi:10.1029/2007GL029683

15. X. Yan, R. Zhang, T. R. Knutson, The role of Atlantic overturning circulation in the recent decline of Atlantic major hurricane frequency. Nat. Commun. 8, 1695 (2017). doi:10.1038/s41467-017-01377-8 Medline

16. T. R. Knutson, J. L. McBride, J. Chan, K. Emanuel, G. Holland, C. Landsea, I. Held, J. P. Kossin, A. K. Srivastava, M. Sugi, Tropical cyclones and climate change. Nat. Geosci. 3, 157-163 (2010). doi:10.1038/ngeo 779

17. H. Murakami, Y. Wang, H. Yoshimura, R. Mizuta, M. Sugi, E. Shindo, Y. Adachi, S. Yukimoto, M. Hosaka, S. Kusunoki, T. Ose, A. Kitoh, Future changes in tropical cyclone activity projected by the new high-resolution MRI-AGCM. J. Clim. 25, 3237-3260 (2012). doi:10.1175/JCLI-D-11-00415.1

18. T. R. Knutson, J. J. Sirutis, M. Zhao, R. E. Tuleya, M. Bender, G. A. Vecchi, G. Villarini, D. Chavas, Global projections of intense tropical cyclone activity for the late twenty-first century from dynamical downscaling of CMIP5/RCP4.5 Scenarios. J. Clim. 28, 7203-7224 (2015). doi:10.1175/JCLI-D-15-0129.1

19. H. Murakami, G. A. Vecchi, S. Underwood, T. L. Delworth, A. T. Wittenberg, W. G. Anderson, J.-H. Chen, R. G. Gudgel, L. M. Harris, S.-J. Lin, F. Zeng, Simulation and prediction of Category 4 and 5 hurricanes in the high-resolution GFDL HiFLOR coupled climate model. J. Clim. 28, 9058-9079 (2015). doi:10.1175/JCLI-D-150216.1

20. H. Murakami, G. A. Vecchi, G. Villarini, T. L. Delworth, R. Gudgel, S. Underwood, X.
Yang, W. Zhang, S.-J. Lin, Seasonal forecasts of major hurricanes and landfalling tropical cyclones using a high-resolution GFDL coupled climate model. J. Clim. 29, 7977-7989 (2016). doi:10.1175/JCLI-D-16-0233.1

21. E. D. Maloney, D. L. Hartmann, Modulation of hurricane activity in the gulf of mexico by the madden-julian oscillation. Science 287, 2002-2004 (2000). doi:10.1126/science. 287.5460 .2002 Medline

22. P. J. Klotzbach, On the Madden-Julian oscillation-Atlantic hurricane relationship. J. Clim. 23, 282-293 (2010). doi:10.1175/2009.JCLI2978.1

23. North American Multi-Model Ensemble (NMME), NMME relative forecast archive; available online

at www.cpc.ncep.noaa.gov/products/NMME/archive/2017040800/current/tmps fc_Seas $2 . h t m l$.

24. W. Duan, C. Wei, The 'spring predictability barrier' for ENSO predictions and its possible mechanism: Results from a fully coupled model. Int. J. Climatol. 33, 1280-1292 (2013). doi:10.1002/joc.3513

25. N. J. Dunstone, D. M. Smith, B. B. B. Booth, L. Hermanson, R. Eade, Anthropogenic aerosol forcing of Atlantic tropical storms. Nat. Geosci. 6, 534-539 (2013). doi:10.1038/ngeo1854

26. M. Ting, S. J. Camargo, C. Li, Y. Kushnir, Natural and forced North Atlantic hurricane potential intensity change in CMIP5 models. J. Clim. 28, 3926-3942 (2015). doi:10.1175/JCLI-D-14-00520.1

27. A. H. Sobel, S. J. Camargo, T. M. Hall, C.-Y. Lee, M. K. Tippett, A. A. Wing, Human influence on tropical cyclone intensity. Science 353, 242-246 (2016). doi:10.1126/science. aaf6574 Medline

28. H. Murakami, G. A. Vecchi, S. Underwood, Increasing frequency of extremely severe cyclonic storms over the Arabian Sea. Nat. Clim. Chang. 7, 885-889 (2017). doi:10.1038/s41558-017-0008-6

29. G. A. Vecchi, B. J. Soden, Effect of remote sea surface temperature change on tropical cyclone potential intensity. Nature 450, 1066-1070 (2007). doi:10.1038/nature06423 Medline

30. G. A. Vecchi, R. Msadek, W. Anderson, Y.-S. Chang, T. Delworth, K. Dixon, R. Gudgel, A. Rosati, B. Stern, G. Villarini, A. Wittenberg, X. Yang, F. Zeng, R. Zhang, S. Zhang, Multiyear predictions of North Atlantic hurricane frequency: Promise and limitations. J. Clim. 26, 5337-5357 (2013). doi:10.1175/JCLI-D-12-00464.1

31. W. Zhang, G. A. Vecchi, H. Murakami, T. Delworth, A. T. Wittenberg, A. Rosati, S. Underwood, W. Anderson, L. Harris, R. Gudgel, S.-J. Lin, G. Villarini, J.-H. Chen, Improved simulation of tropical cyclone responses to ENSO in the western North Pacific in the high-resolution GFDL HiFLOR Coupled Climate Model. J. Clim. 29, 1391-1415 (2016). doi:10.1175/JCLI-D-15-0475.1

32. H. Murakami, B. Wang, T. Li, A. Kitoh, Projected increase in tropical cyclones near Hawaii. Nat. Clim. Chang. 3, 749-754 (2013). doi:10.1038/nclimate1890

33. J.-H. Chu, C. R. Sampson, A. S. Levin, E. Fukada, The Joint Typhoon Warning Center tropical cyclone best tracks 1945-2000, Joint Typhoon Warning Center Rep., Pearl Harbor, HI, 22pp.; available online at www.usno,navy.mil/NOOC/nmfc-ph/RSS/jtwc/best_tracks/TC_bt_report.html (2002).

34. K. R. Knapp, M. C. Kruk, D. H. Levinson, H. J. Diamond, C. J. Neumann, The international best track archive for climate stewardship (IBTrACS): Unifying tropical cyclone best track data. Bull. Am. Meteorol. Soc. 91, 363-376 (2010). doi:10.1175/2009BAMS2755.1

35. Tropical Cyclone Guidance Project, available online at http://hurricanes, ral.ucar.edu/repository/.

36. N. A. Rayner, D. E. Parker, E. B. Horton, C. K. Folland, L. V. Alexander, D. P. Rowell, Global analysis of sea surface temperature, sea ice, and night marine air temperature since the late nineteenth century. J. Geophys. Res. 108, 4407 (2003). doi:10.1029/2002JD002670

37. B. Huang, P. W. Thorne, V. F. Banzon, T. Boyer, G. Chepurin, J. H. Lawrimore, M. J. Menne, T. M. Smith, R. S. Vose, H.-M. Zhang, coauthors. Extended Reconstructed Sea Surface Temperature version 5 (ERSSTv5), Upgrades, validations, and intercomparisons. J. Clim. 30, 8179-8205 (2017). doi:10.1175/JCLI-D-16-0836.1

38. M. Ishii, A. Shouji, S. Sugimoto, T. Matsumoto, Objective analyses of sea-surface temperature and marine meteorological variables for the 20th century using ICOADS and the Kobe collection. Int. J. Climatol. 25, 865-879 (2005). doi:10.1002/joc.1169

39. H. Murakami, G. A. Vecchi, T. L. Delworth, A. T. Wittenberg, S. Underwood, R. 
Gudgel, X. Yang, L. Jia, F. Zeng, K. Paffendorf, W. Zhang, Dominant role of subtropical Pacific warming in extreme eastern Pacific hurricane seasons: 2015 and the future. J. Clim. 30, 243-264 (2017). doi:10.1175/JCLI-D-16-0424.1

40. L. Jia, X. Yang, G. A. Vecchi, R. G. Gudgel, T. L. Delworth, A. Rosati, W. F. Stern, A. T. Wittenberg, L. Krishnamurthy, S. Zhang, R. Msadek, S. Kapnick, S. Underwood, F. Zeng, W. G. Anderson, V. Balaji, K. Dixon, Improved seasonal prediction of temperature and precipitation over land in a high-resolution GFDL climate model. J. Clim. 28, 2044-2062 (2015). doi:10.1175/JCLI-D-14-00112.1

41. L. M. Harris, S.-J. Lin, C. Y. Tu, High resolution climate simulations using GFDL HiRAM with a stretched global grid. J. Clim. 29, 4293-4314 (2016). doi:10.1175/JCLI-D-15-0389.1

42. S. Kobayashi, Y. Ota, Y. Harada, A. Ebita, M. Moriya, H. Onoda, K. Onogi, H. Kamahori, C. Kobayashi, H. Endo, K. Miyaoka, K. Takahashi, The JRA-55 reanalysis: General specifications and basic characteristics. J. Meteorol. Soc. Jpn. 93, 5-48 (2015). doi:10.2151/jmsj.2015-001

43. R. Gelaro, W. McCarty, M. J. Suárez, R. Todling, A. Molod, L. Takacs, C. A. Randles, A. Darmenov, M. G. Bosilovich, R. Reichle, K. Wargan, L. Coy, R. Cullather, C. Draper, S. Akella, V. Buchard, A. Conaty, A. M. da Silva, W. Gu, G.-K. Kim, R. Koster, R. Lucchesi, D. Merkova, J. E. Nielsen, G. Partyka, S. Pawson, W. Putman, M. Rienecker, S. D. Schubert, M. Sienkiewicz, B. Zhao, The Modern-Era Retrospective Analysis for Research and Applications, Version 2 (MERRA-2). J. Clim. 30, 54195454 (2017). doi:10.1175/JCLI-D-16-0758.1

44. D. P. Dee, S. M. Uppala, A. J. Simmons, P. Berrisford, P. Poli, S. Kobayashi, U. Andrae, M. A. Balmaseda, G. Balsamo, P. Bauer, P. Bechtold, A. C. M. Beljaars, L. van de Berg, J. Bidlot, N. Bormann, C. Delsol, R. Dragani, M. Fuentes, A. J. Geer, L. Haimberger, S. B. Healy, H. Hersbach, E. V. Hólm, L. Isaksen, P. Kållberg, M. Köhler, M. Matricardi, A. P. McNally, B. M. Monge-Sanz, J.-J. Morcrette, B.-K. Park, C. Peubey, P. de Rosnay, C. Tavolato, J.-N. Thépaut, F. Vitart, The ERA-Interim reanalysis: Configuration and performance of the data assimilation system. Q. J. R. Meteorol. Soc. 137, 553-597 (2011). doi:10.1002/qj.828

\section{ACKNOWLEDGMENTS}

The authors thank Dr. Xiaogin Yan, Dr. Mitchell Bushuk, and Dr. Kun Gao, and two anonymous reviewers for their suggestions and comments. The statements, findings, conclusions, and recommendations are those of the authors and do not necessarily reflect the views of the National Oceanic and Atmospheric Administration, or the U.S. Department of Commerce. Funding: H.M. prepared this report under award NA140AR4320106 (The Cooperative Institute for Climate Science) and NA140AR4830101 (The Sandy Supplemental) from the National Oceanic and Atmospheric Administration, U.S. Department of Commerce. Author contributions: H.M. designed the study, carried out the experiments, analyzed the results, and wrote the manuscript. R.G. carried out the retrospective and real-time seasonal forecasts. E.L analyzed the observed MH frequency and climate indices. R.G., T.L.D and P.H. discussed the results with H.M. and made comments on the manuscript. Competing interests: The authors declare no competing financial interests. Data and materials availability: The source code of the climate model can be accessed at www.gfdl.noaa.gov/cm2-5-and-flor/. The predicted tropical cyclone tracks through the idealized experiments are online available at $\mathrm{ftp}$ ///nomads.gfdl.noaa.gov/users/Hiroyuki.Murakami/GFDLHiFLOR/2017MH/.

\section{SUPPLEMENTARY MATERIALS}

www.sciencemag.org/cgi/content/full/science.aat6711/DC1

Materials and Methods

Figs. S1 to S8

Tables S1 and S2

References (33-44)

22 March 2018; accepted 14 September 2018

Published online 27 September 2018

$10.1126 /$ scienceaat 6711 
(a) Tropical Cyclones in 2017 (July-November)

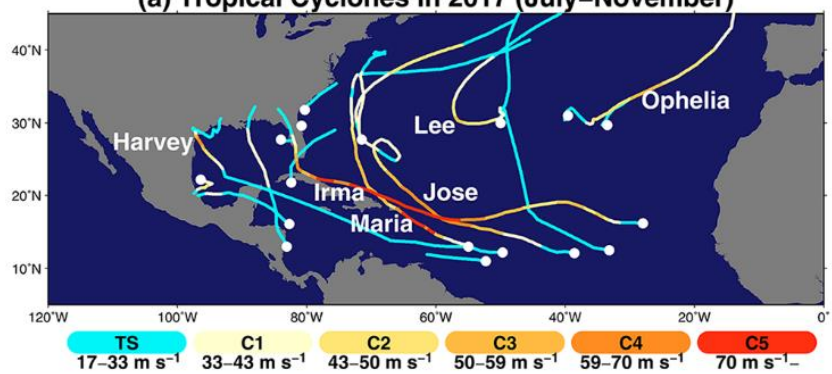

(c) Observed 2017 MH Density Anomaly

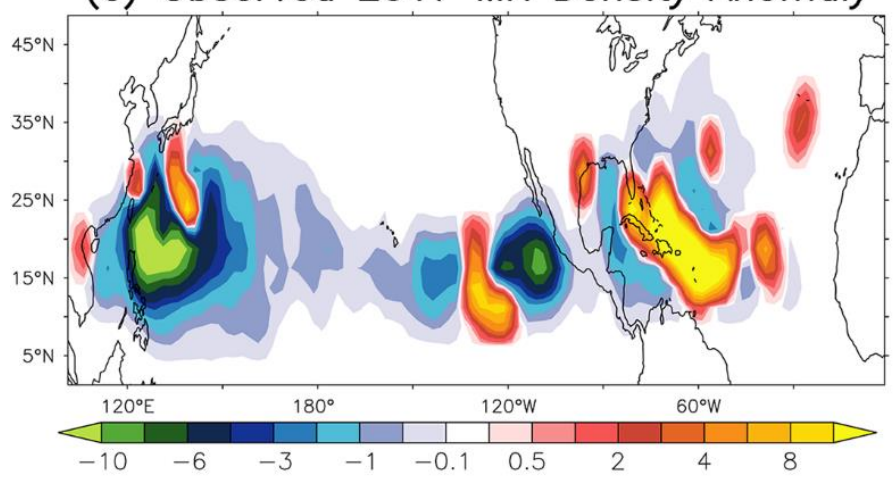

(e) Predicted 2017 MH Density Anomaly

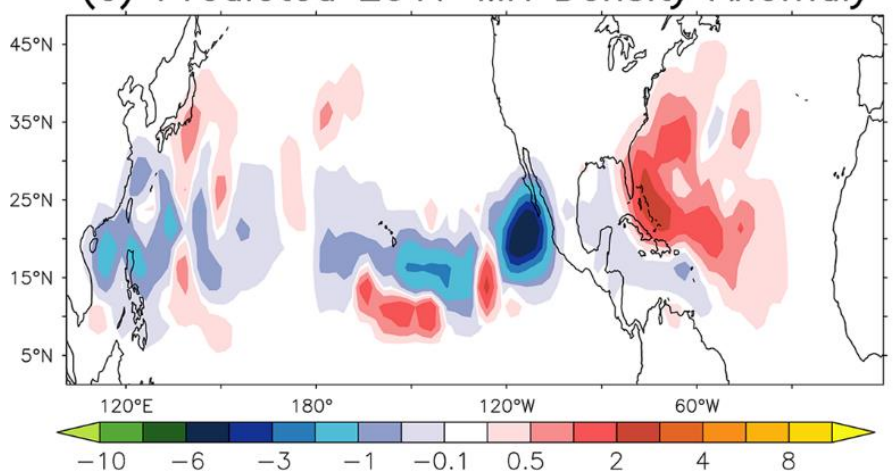

(b) MH Frequency and Climate Indices (July-November)

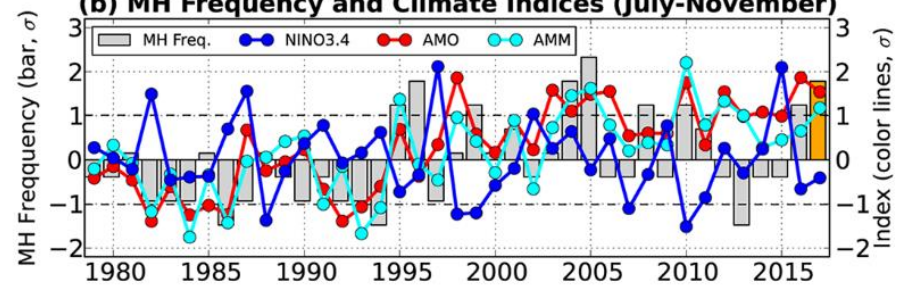

(d) Observed 2017 SST Anomaly

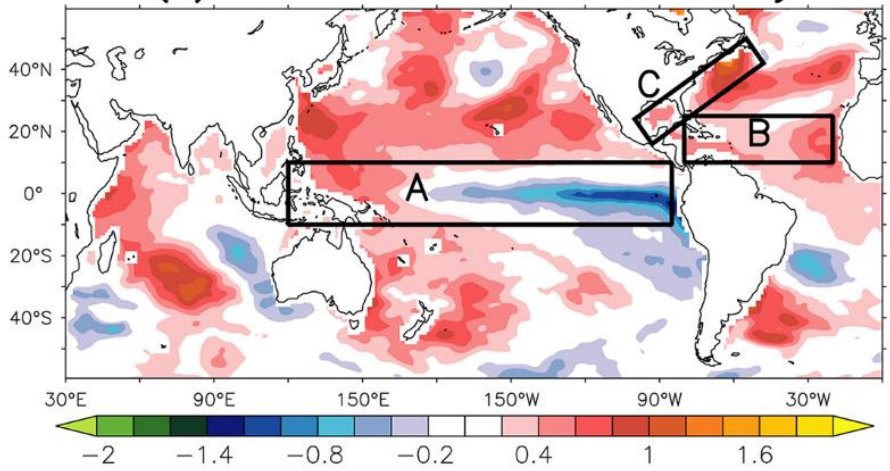

(f) Predicted 2017 SST Anomaly

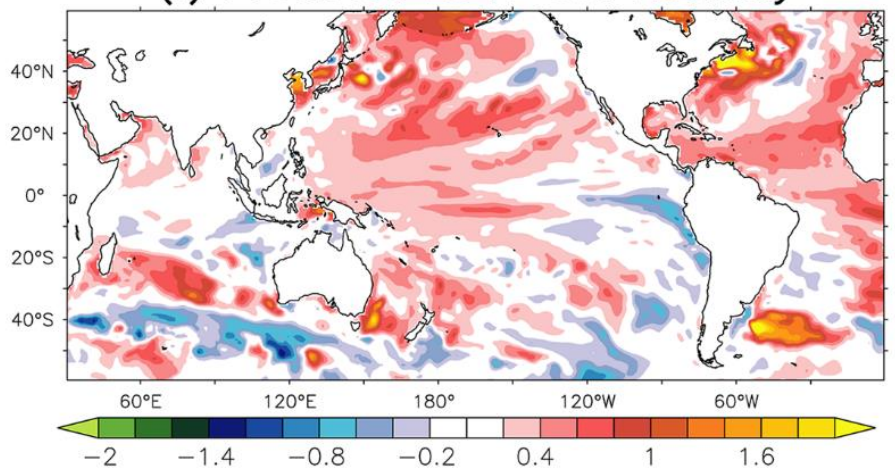

Fig. 1. Observed and predicted Major Hurricanes (MHs) and SSTs in 2017. (A) Observed tropical cyclones during the hurricane season in 2017. Storm tracks are colored according to the intensities of the storms, as categorized by the Saffir-Simpson hurricane wind scale (TS, tropical storm; C1-C5, category 1 to category 5 hurricanes). Labeled storms denote MHs. (B) Standardized index $(\sigma)$ for the observed anomaly of MH frequency (gray bars), along with the observed standardized index $(\sigma)$ of the natural variability (colored lines) for the Niño3.4 (blue), AMO (red), and AMM (cyan) indices. The yellow bar highlights the observed $2017 \mathrm{MH}$ anomaly. (C) Observed MH density anomaly in the 2017 hurricane season relative to the mean of 1980-2017 (number per $2.5^{\circ} \times 2.5^{\circ}$ grid box per season). (D) Observed SST anomaly (SSTA, units: K) in the 2017 hurricane season relative to the mean of the period 1982-2012. The black frames are the possible key regions for the unusually high MH activity in 2017. (E and F) As in (C) and (D) but for ensemble mean of real-time seasonal predictions from 1 July 2017 initials predicted by HiFLOR. 
(a) $\mathrm{CLIM+}$

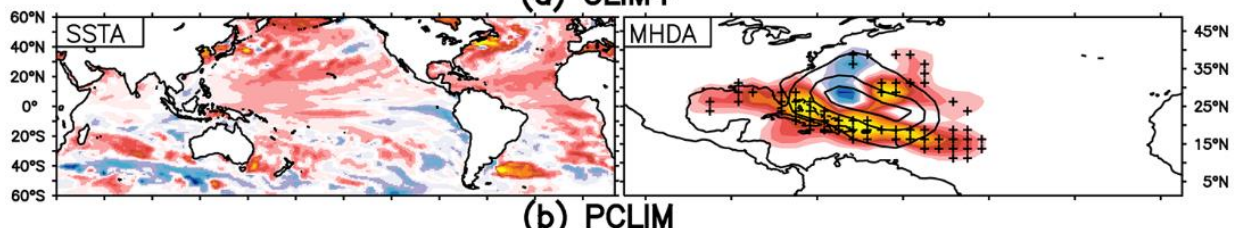

(b) PCLIM

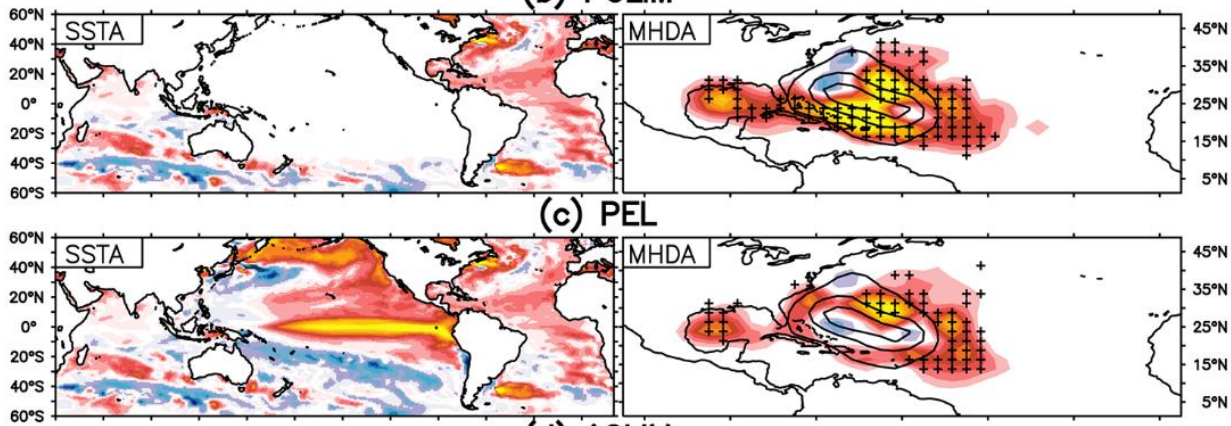

(d) ACLiM
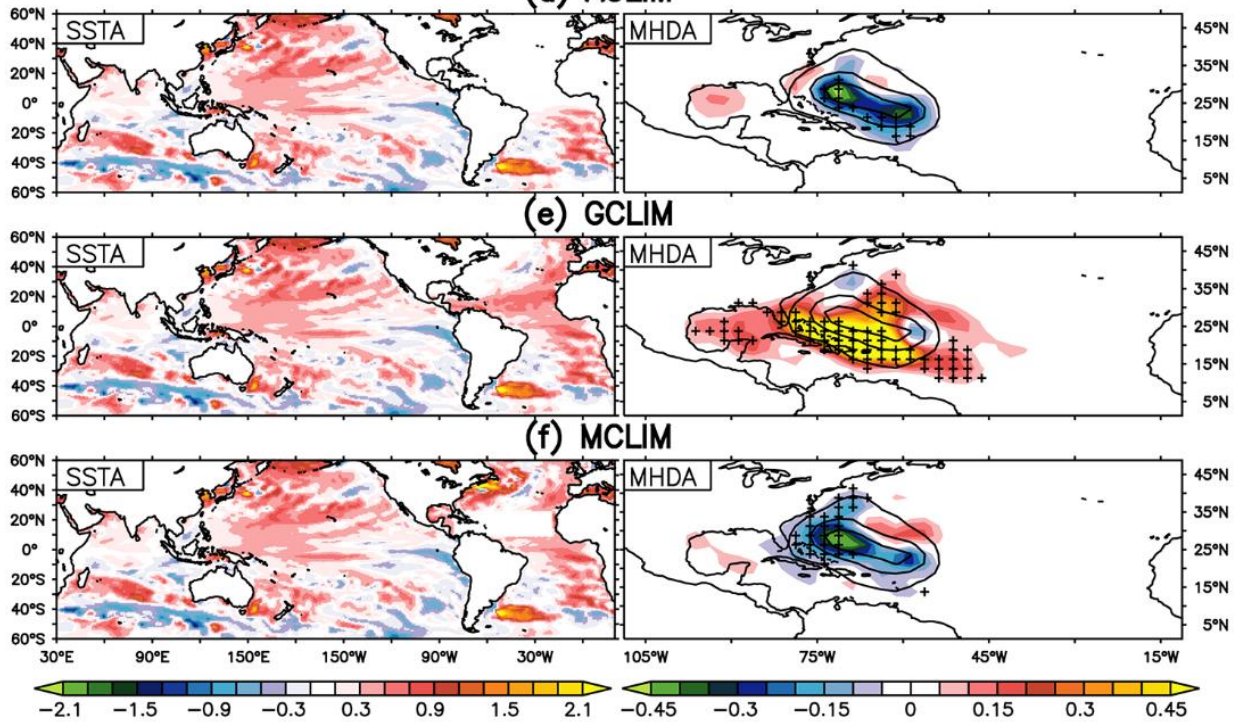

Fig. 2. Prescribed idealized SSTA and predicted MH density. Idealized seasonal forecasts conducted by prescribing the idealized SSTs in which SST anomalies (SSTAs; left-hand panels; units: K) are superimposed onto the climatological mean SST (CLIM). The resultant predicted MH density anomalies (MHDAs) relative to the CLIM experiment are shown by the shading in the right-hand panels (units: number per season). The prescribed SSTAs are: (A) all 2017 anomalies (CLIM+); (B) as in CLIM+, except the Pacific SSTAs are set to zero (PCLIM); (C) as in CLIM+, except the Pacific SSTA is replaced with the SSTA predicted by 1 April 2017 initial predictions, predicting El Niño conditions (PEL); (D) as in CLIM+, except the Atlantic SSTA is set to zero (ACLIM); (E) as in CLIM+, except the SSTA off the coast of North America is set to zero (GCLIM); and (F) as in CLIM+, except the SSTA in the tropical Atlantic is set to zero. Contours in the righthand panels denote the mean $\mathrm{MH}$ density predicted from the CLIM experiment. The contour interval is 0.6 per season. Cross marks in the righthand panels indicate the predicted change relative to the CLIM experiment is statistically significant at the $90 \%$ confidence level or above [boot strap method proposed by Murakami et al. (32)]. 


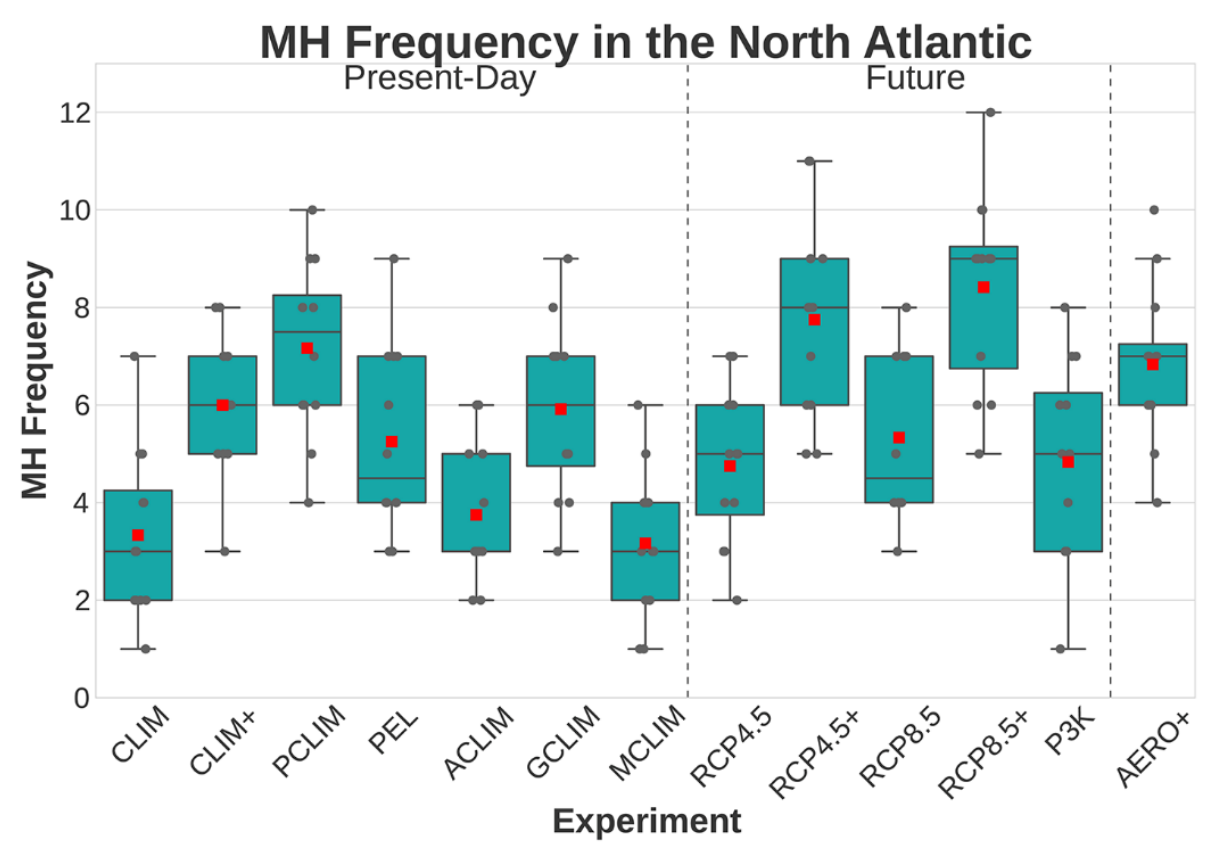

Fig. 3. Box plots for the predicted MH frequency over the North Atlantic according to various prescribed SSTA patterns. The red squares denote the ensemble mean, while the black dots show each ensemble member. The boxes represent the lower and upper quartiles; the horizontal lines in the middle show the median value; and the horizontal end lines show the lowest (highest) datum still within the 1.5 interquartile range (IQR) of the lower (upper) quartile. 
(a) RCP4.5 - CLIM

(b) RCP8.5 - CLIM

(c) $2015 \mathrm{Cntl}-1940 \mathrm{Cntl}$

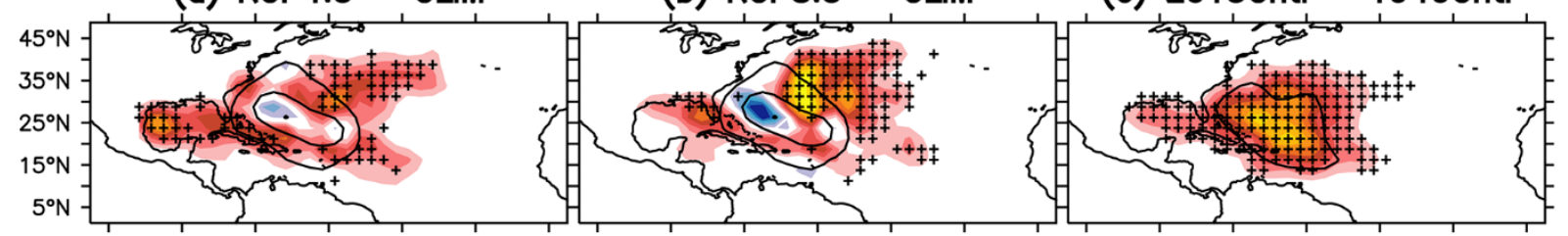

(d) RCP4.5+ - RCP4.5

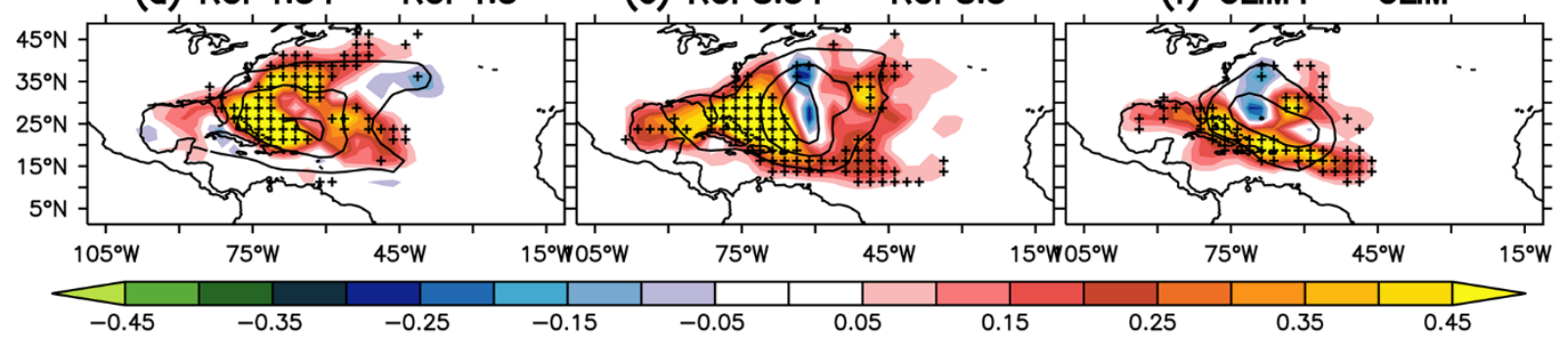

Fig. 4. Projected changes in $\mathrm{MH}$ density in the future experiments. Projected change in the July-November mean MH density (number per season), based on (A) RCP4.5 relative to CLIM, (B) RCP8.5 relative to CLIM, (C) 2015Cntl relative to $1940 \mathrm{CntI}$, (D) RCP4.5+ relative to RCP4.5, (E) RCP8.5+ relative to RCP8.5, and (F) CLIM+ relative to CLIM. Cross marks indicate the predicted change is statistically significant at the $90 \%$ confidence level or above [boot strap method proposed by Murakami et al. (32)]. Contours show the predicted values for the reference experiment [i.e., CLIM for (A), (B), and (F); 1940Cntl for (C); RCP4.5 for (D); and RCP8.5 for (E)]. The contour interval is 0.6 per season. 
(a) MDR SSTA (Present-day Only)

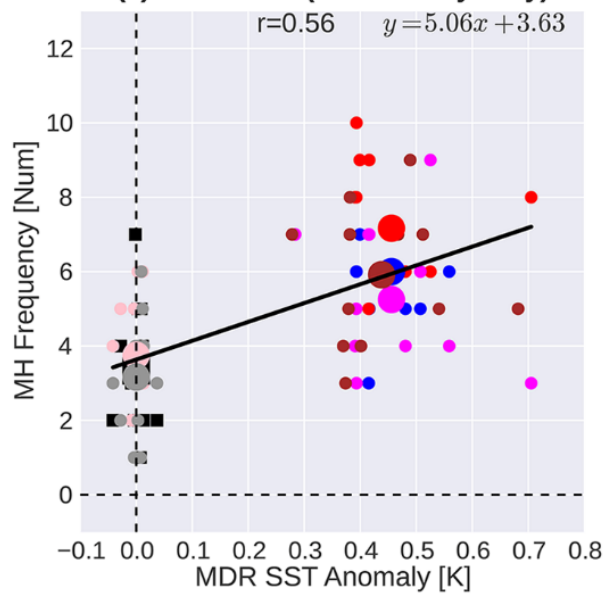

(c) MDR SSTA (Present-day \& Future)

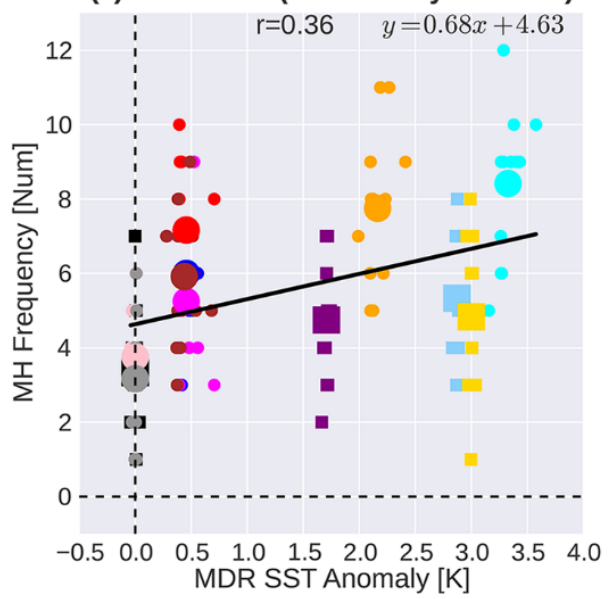

(b) MDR RSSTA (Present-day Only)

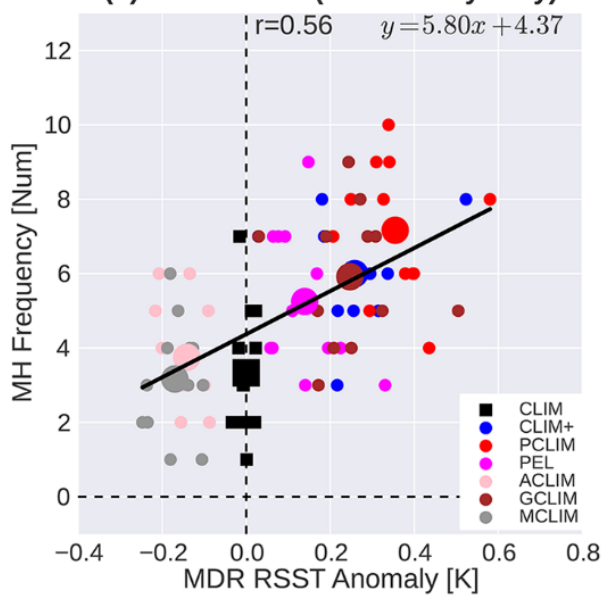

(d) MDR RSSTA (Present-day \& Future)

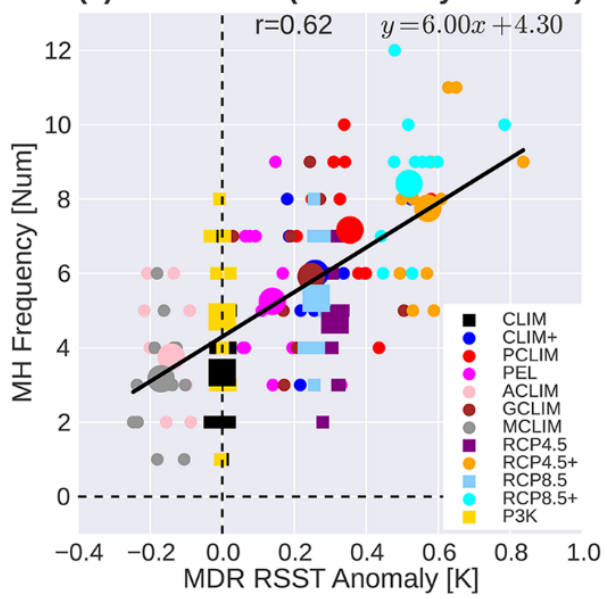

Fig. 5. Relationship between the predicted $M H$ frequency and prescribed MDR SSTA or RSSTA. (A) MH frequency and MDR SSTA for the present-day experiments. (B) As in (A) but for the MH frequency and MDR RSST. (C and D) As in (A) and (B) but with the future experiments as well as the present-day experiments included. The small (large) symbols denote each ensemble member (the ensemble mean). The black line denotes the linear regression line. The correlation coefficient $(r)$ and linear-regression equation are displayed at the top of each panel. 